\title{
The strategies for an organizational self-assessment of diversity-inclusiveness of policy and practice in a hospital setting
}

\author{
Sylvia Reitmanova, Denise L. Spitzer \\ Faculty of Social Sciences, University of Ottawa, Ottawa, Canada \\ Correspondence: Sylvia Reitmanova. Address: Faculty of Social Sciences, University of Ottawa, Ottawa, Ontario, K1N \\ 6N5, Canada. E-mail: sreitman@uottawa.ca \\ Received: September 30, 2013 \\ DOI : $10.5430 /$ jha.v3n3p81 \\ Accepted: January 6, 2014 \\ URL: http://dx.doi.org/10.5430/jha.v3n3p81 \\ Online Published: January 22, 2014
}

\begin{abstract}
Drawing on the data collected through anonymous semi-structured surveys with four clinical nurse managers and 70 female hospital service users of various minority backgrounds, this study examined how the reproductive health needs of minority women were addressed by healthcare services in the Ottawa Hospital. Participating minority women included non-white Canadian-born women, Aboriginal women, immigrant women, single mothers-by-choice, women with disabilities as well as lesbian and bisexual women in reproductive age. The results indicated that there is great room for improving inclusivity and equity in all aspects of hospital operations: institutional policies and practices, service planning, staff recruitment and training, as well as physical environment and health education materials. A considerable number of surveyed women reported that their cultural, social, linguistic, physical and mental needs were not satisfactory addressed, or understood and respected by hospital staff. The majority of women also indicated that the hospital ambiance and health education materials did not reflect their minority status or their ideas and experiences of health and maternity. The study findings provide an important ground-work for an organizational self-assessment of diversity-inclusiveness of hospital policies and practices of individual healthcare professionals. The assessment of these policies and practices is the first step toward the improvement of quality of service for minority women and building a healthier and more equitable working environment for hospital employees.
\end{abstract}

\section{Key words}

Hospital, Reproductive health, Diversity, Inclusiveness, Accessibility

\section{I ntroduction}

\subsection{Diversity, inclusion and reproductive healthcare in Canada}

In Canada, a number of studies have suggested that women from minority populations experience many inequities and unmet needs in the area of reproductive health. For instance, some groups of non-white immigrant women and Aboriginal women are disadvantaged by the lack of services responsive to their cultural health beliefs, values, and practices, linguistic needs and also to their experiences of poverty and racism ${ }^{[1-4]}$. The provision of services for mothers with disabilities is also a challenging issue for many healthcare providers who have difficulty dealing with pregnant women with disabilities ${ }^{[5]}$. 
According to Ontario's Disabled Women's Network (DAWN), support and services for these women either do not exist or are almost inaccessible. Very little is known about the challenges and specific healthcare or reproductive care needs of lesbian, bisexual and transgender people who, according to Rainbow Health Ontario, underutilize healthcare services due to their experiences of prejudice and discrimination compounded by the lack of culturally competent care ${ }^{[6]}$.

Providing diversity-inclusive reproductive healthcare is essential for ensuring optimal health outcomes for mothers (and their children) from minority populations. There is ample support in the literature for the benefits of developing such inclusiveness in healthcare institutions ${ }^{[7-9]}$. Several studies showed that the lack of competent services which would address effectively women's needs can add to stress-induced hormonal and immune responses making women more vulnerable to pre-term labour, low birth weight, and perinatal mortality and morbidity including gestational diabetes and post-partum depression ${ }^{[10-12]}$. The negative experiences with the provision of appropriate healthcare services may be also destructive to women's decisions to utilize services in the future ${ }^{[13]}$. In addition to the listed benefits of providing diversity-inclusive services, it must be noted that the provision of such services is in compliance with the right to equal treatment entrenched in both the Canadian Charter of Rights and Freedoms, and provincial Human Rights Codes.

Some Canadian healthcare institutions have already put in place a set of policies and practices that can enable health professionals to be effective in delivering care in cross-cultural situations ${ }^{[14,15]}$. However, the understanding of diversity in the healthcare institutions which enacted these policies and practices is often limited to differences in women's ethnic background, skin colour, culture, religion and language. Our understanding of diversity is much broader and expands beyond these five categories of difference to include the factors such as gender identity, sexual orientation, age, mental or physical ability, literacy level, and family status, to name just a few ${ }^{[16]}$. These factors determine the reproductive health needs of minority women in multiple similar and different ways. However, the information about how are these diversity-derived needs accommodated within reproductive healthcare institutions is very limited. For this reason, in this study we examined the current status of diversity-inclusiveness of policies and practices implemented in the provision of reproductive health services in the largest hospital in the nation's capital, Ottawa. Our objective was to identify reproductive health needs of minority women and inform the development of diversity-inclusive policies and practices which would cater to these health needs. Not only can the inclusive hospital environment impact positively on well-being of patients through the improved quality of care but workplace inclusivity enhances relationship building with the larger community and within the organization itself. An inclusive environment improves morale among all employees, builds organizational capacity and expertise, decreases conflict and makes the roots of conflict better understood ${ }^{[16]}$. It also complies with relevant legislation, supports risk management, and protects the organization from liability.

\subsection{Reproductive healthcare policy and practice in the Ottawa Hospital}

The statistical data on the diversity of Ottawa's female population provide a sound rationale for carrying out this project in the national capital. According to Census 2006, out of 419,130 Ottawa's female residents, $43 \%(n=178,735)$ were women of reproductive age between the ages of 15 and $45^{[17]}$. About $20 \%$ of women $(n=83,200)$ identified themselves as visible minorities. Foreign-born immigrant women represented about $22 \%(n=93,425)$ of all women. Aboriginal women constituted 2\% $(n=6,625)$ of the total female population. Approximately the same percentage of women was categorized as belonging to linguistic minorities with no knowledge of any of the two Canada's official languages: English and French. Regrettably, current data regarding religious affiliation are not yet available. Although Statistics Canada does not provide the information on the definitive number of people from sexual and transgender minorities, there is an active community of these minorities in Ottawa. Women with disabilities constitute also an important membership in the community. According to Ottawa's Social Planning Council, almost $16 \%(n=65,290)$ of the city's female population lived with activity limitations due to disability ${ }^{[18]}$.

Many Ottawa women seek reproductive healthcare offered at three different campuses of the Ottawa Hospital, one of the largest healthcare provider in the Eastern Ontario. The hospital provides a variety of reproductive health services such as, for instance, antenatal and postnatal consultation clinics and home care programs, contraception clinic, maternal-fetal 
medicine clinic for high-risk pregnancies, birthing services, mother baby care, breastfeeding consultation, pre-menstrual syndrome clinic, menopause clinic, and women's breast health centre. Women can also benefit from other services offered to patients seeking reproductive healthcare such as perinatal mental health, sexual assault and partner abuse care program, and spiritual care services. Healthcare providers in women's health clinics and obstetrics clinics annually see about 68,000 female patients. In the 2011-12 annual report there were about 6,631 births recorded in the hospital ${ }^{[19]}$.

According to the hospital website, the institution positions itself as a compassionate provider of patient-centred health services with an emphasis on tertiary-level and specialty care. Its mission is to function in English and French while striving to meet the needs of the culturally diverse community. There are three important external drivers behind the hospital policies and services. The first driver is the patient declaration of values the hospital developed upon the consultation with community stakeholders. Some of these declarations speak to the issue of diversity-inclusiveness; although, the term diversity is not explicitly mentioned ${ }^{[20]}$ :

- We will greet you warmly and introduce ourselves by name and role.

- We will listen with care and we will communicate clearly.

- We will ensure that you are cared for in the official language of your choice (English or French).

- We will be polite and respectful of your cultural values, personal beliefs and abilities.

- We will treat you as the most important member of our patient-care team and will include you and your family in decisions about your care.

- We will go out of our way to meet your needs and keep you informed by explaining what we are doing and letting you know what to expect.

- We will maintain the highest level of professional standards, skills and competence.

- We will practice safe care in everything we do, from cleaning our hands to ensuring the safety of our environment, technologies and processes. Your safety is our top priority.

- We will protect your privacy and maintain your personal dignity.

- We will acknowledge and apologize when a problem occurs. We will actively listen and correct the problem.

The second driver is The Ontario's Excellent Care for All Act, according to which, the hospital was expected to develop Quality Improvement Plan in 2012. The plan focuses on enhancing its performance along five dimensions: safety, effectiveness, access, patient-centeredness, and integration ${ }^{[21]}$. The plan aims, for instance, to increase patients' satisfaction through clearer communication about and with patients. Unfortunately, the issue of diversity and inclusion is not mentioned in this document.

The third driver is The Integrated Accessibility Standards Regulation which requires hospitals to address the barriers experienced by persons with disabilities in its by-laws, policies, programs, and services. As of 2013, the hospital plans to develop a Multi-year Accessibility Plan to outline strategies on the removal and prevention of physical, communication and attitudinal barriers that persons with disabilities frequently encounter. This new plan should advance the Accessibility Plan already in place which sets out policies, practices and procedures on providing goods or services to people with disabilities ${ }^{[22]}$. According to these policies, the consideration of a person's disability should be reflected in communication process, permission to use assistive devices or support persons receive on the hospital premises. The hospital should actively document a feedback on how its goods or services are provided to people with disabilities. Importantly, according to the plan, the hospital should train all its employees, volunteers and contractors in providing goods or services to people with disabilities. 
The review of these and other documents available on the hospital website suggests that only persons with disabilities and francophone persons are considered a special category of patients whose needs should be addressed by the policies entrenched in the hospital plans. While the hospital declares its respect of patients' cultural values, personal beliefs and abilities, there are no official policies on the removal and prevention of physical, communication and attitudinal barriers for persons from minority cultural communities such as, for instance, Aboriginals, immigrants, non-English and non-French speakers, or lesbian, bisexual and transgender persons. As we will show in the study results, this problem of an insufficient inclusion of diversity within the hospital policies and practices was manifested in the answers to the surveys we administered to our research participants.

\section{Methods}

The approval for this study was obtained from two research ethics boards. In the first phase, during May and July 2012, we invited in person seven clinical nurse managers responsible for providing operational oversight, quality assurance, patient safety, risk management, and strategic planning for reproductive health services in the Ottawa Hospital to participate in this study. In addition to their involvement with budget management, administration, and bed flow co-ordination, these managers were in charge of overseeing nursing staff's compliance with established policies, procedures and protocols. Their responsibilities also included ensuring that their units have appropriate staffing, and staff members have appropriate equipment and resources they need to perform their duties. Four managers mailed back an anonymous semi-structured self-assessment survey designed to measure the hospital inclusiveness across five main domains: organizational policies and practices; service planning; staff recruitment and retention; staff and volunteer training; and physical environment, materials and resources. The survey was a modified version of an organizational self-assessment tool developed by the Ontario Healthy Communities Coalition ${ }^{[16]}$ and a self-assessment tool for healthcare managers developed by Nova Scotia Department of Health ${ }^{[15]}$.

In the second phase, during January and March 2013, women of various minority backgrounds were invited by an advertisement flyer to complete the anonymous surveys and place them in dropboxes in the waiting areas of the hospital reproductive health clinics. Some survey participants were also recruited in the university health clinic. Furthermore, the study was widely advertised in a variety of mailing lists and websites with the assistance of numerous providers of healthcare and community services who work with minority women. For instance, some Aboriginal women were recruited at the Odawa Native Friendship Centre with the help of a local family support worker. The survey was also posted online at www.surveymonkey.com and advertised through Facebook postings. A call for participants was published in a local non-mainstream media outlet targeting Muslim immigrants in the Ottawa region because Muslim women were identified by clinical nurse managers in the first phase of the project as one of the major groups seeking reproductive healthcare in the Ottawa Hospital.

The survey was comprised of 15 questions. Beside age, minority status, and also the type and length of service use, study participants were asked to identify their access barriers (if any), and provide examples how could hospital services address their cultural, social, linguistic, mental and physical needs to their satisfaction. A Likert Scale was used to seek women's opinion whether hospital staff understood and respected their needs; whether pictures, posters, and artwork displayed in the hospital reflected their minority status; and whether health education materials reflected their ideas and experiences of health, reproduction and baby care. Participants were also asked to suggest various mechanisms by which the hospital could consult service users about their needs. The completed surveys were collected on a weekly basis by the principal investigator and added to the data entry manager provided by the www.surveymonkey.com which already contained the surveys submitted online. The online surveys were all assigned different computer IP addresses. In total, eight surveys were excluded from the collected pool of 78 because they missed the information on the minority status. The data were analyzed quantitatively as total or cross-tabulated frequencies. The qualitative content analysis was also performed. Participants' responses and short comments were used in determining the examples of good practices and making recommendations for policy and practice change. 


\section{Results}

\subsection{Survey for managers: Measures of diversity-inclusiveness in hospital policy and practice}

\subsubsection{Organizational policies and practices}

All participating managers were aware that the Ottawa Hospital has in place anti-discrimination and workplace harassment policies as well as written procedures for handling complaints of discrimination. However, managers indicated that they did not know if the hospital examined these policies to identify employees' and patients' barriers to inclusion. They were also unaware whether the hospital developed a strategic action plan to address the issues of diversity, inclusion and discrimination and if this plan is monitored, reviewed and evaluated. Three managers were unaware if staff is involved in providing input in the strategic plan and if resources are available to support the plan. One manager expressed the need to work on involving staff and gathering resources to address the issue of diversity and inclusiveness in the hospital.

\subsubsection{Service planning}

Only one manager was aware of the hospital access to an updated demographic profile and healthcare needs of the community served. Three managers thought the hospital needs to improve communication and outreach strategies to provide necessary information to the served communities and consult community representatives on service planning. One manager indicated that the hospital does not monitor the accessibility, appropriateness and effectiveness of programs and services for minority communities and it also does not have resources needed to provide services responsive to the identified needs of minority communities. Other managers either did not have knowledge about these issues or thought the services need an improvement.

\subsubsection{Staff recruitment and retention}

While two managers indicated that the hospital explored barriers to recruitment, hiring, promotion and retention of members of diverse minority groups as staff, volunteers and partners, two other managers were unaware of such an exploration taking place. In addition, three managers had no knowledge if the hospital advertises employment opportunities in non-mainstream media. Managers also did not know if job opportunities are advertised in a variety of languages including, for instance, Braille.

\subsubsection{Staff and volunteer training}

Managers either indicated that the hospital does not have any training and assessment programs to measure the knowledge and skills of staff and volunteers in the areas of diversity, equity and inclusion or they were unaware of such programs. They expressed that the hospital should work on developing these training and assessment programs; however, they were not aware if the hospital has resources to develop such programs. They were also unaware if minority communities are involved in the planning, delivery and evaluation of any existing diversity, equity and inclusion education/training programs. Only one manager noted that the hospital developed clear guidelines for staff to provide inclusive services. However, the provision of inclusive services was likely not included in the performance appraisal of staff. Managers were unaware if volunteers who promote diversity and inclusion in the hospital are given special consideration for their contributions.

\subsubsection{Physical environment, materials, and resources}

One manager indicated that her unit does not display pictures, posters, artwork and other décor that reflect the clientele's diverse background. Other managers also noted this area needs an improvement. The similar improvement is also needed in the provision of health education materials displayed in reception areas and used by healthcare providers so they can reflect more accurately the diversity and the needs of the served community. Three managers indicated that the hospital employs a variety of communication styles with their clients. However, one manager indicated this includes the French 
language only. Another manager noted that hiring translators is expensive and inconvenient. She thought that some teachable moments with patients get lost while waiting for translators to come to the hospital. In addition, a lot of teaching must occur in one session whenever the translator is available to decrease the frequency of calling translators in.

\subsection{Survey for women: Diversity-derived health needs and experiences}

Out of 70 women who responded to the anonymous semi-structured surveys, 38 (54.3\%) belonged to the age range 25-34, and 21 women (30\%) were in the age category of 35-44. Seven women (10\%) were older than 45 years of age while four women (5.7\%) indicated their age within the range of $15-24$. The table illustrated that the women who took part in the survey had various minority backgrounds both single and intersecting.

Table. Survey participants by minority status

\begin{tabular}{lll}
\hline Minority Status & Response Count & Response Percent \\
\hline Canadian-born non-white (some Muslim) & 10 & 14.3 \\
Canadian-born white (all Muslim) & 3 & 4.3 \\
Canadian-born white (francophone) & 1 & 1.4 \\
Canadian-born mixed ethnicity & 1 & 1.4 \\
Immigrant or refugee non-white (some Muslim, African, Somali, Arab, and & 27 & 38.6 \\
Indian, one francophone, one disability) & 11 & 15.7 \\
Immigrant or refugee white (one francophone) & 7 & 10 \\
Aboriginal & 4 & 5.7 \\
Single mothers by choice (one non-white immigrant and one with a disability) & 2.9 \\
Lesbian & 2 & 4.3 \\
Bisexual (one Canadian-born non-white) & 3 & 4.3 \\
Disability (one non-white immigrant, one single mother by choice) & 3 & \\
\hline
\end{tabular}

\subsubsection{The use of and access to reproductive health hospital services}

Twenty-one participating women (30\% of the total) indicated that they used reproductive health services in the Ottawa Hospital for less than one year while 27 women (38.6\%) used them between one to five years and 22 women (31.4\%) used them for more than five years. Women used a variety of reproductive and additional services offered in the Ottawa Hospital. More than 50 women used ultrasound and birthing services and more than 20 women sought breastfeeding consultations. Mother-baby care, newborn intensive care, special pregnancy services and pre-birth clinic were used by less than 20 but more than 10 women. Post-birth home care and consultation, services at contraception clinic and breast health centre, mental health services were used by less than 10 women. Only one woman accessed language translation and cultural consultation. In addition, one woman indicated she used spiritual care.

The survey showed that 57 women (81.4\%) could easily access the above mentioned services. By contrast 13 women (18.6\%), mainly non-white immigrants or refugees, described several access barriers such as commuting difficulties, long wait lists, the lack of available linguistic translation and cultural interpretation services, as well as the lack of choice of obstetrician. One woman indicated that she "did not even know about most of these services" until she completed the survey. Nine women who experienced access barriers used the services less than five years (including five women who used them less than one year). It is possible that women who are relatively new service users experience more difficulties in accessing healthcare services than women who have already long-term experiences.

\subsubsection{Meeting women's cultural, social, linguistic, physical and mental needs in the hospital}

Out of 70 surveyed women, 44 (62.9\%) indicated that they were not asked about their cultural, social, linguistic, physical and mental needs by the hospital staff when seeking reproductive services. Twelve women (17.1\%) could not recall if they were asked about their needs. Only nine women (12.9\%) indicated that the hospital staff asked them about their needs. 
Since the majority of women were not asked about their needs, not so surprisingly, almost half of the respondents $(\mathrm{n}=32$, 45.7\%) suggested that their needs were not addressed to their satisfaction.

As for women's physical and mental needs abilities, 33 women (47.1\%) believed their needs were addressed in the hospital to their satisfaction. The survey showed that three women, for instance, took the advantage of utilizing mental health services available to women who seek reproductive healthcare. While 24 women (34.3\%) thought the question on meeting their physical and mental abilities and needs did not apply to them, still 12 women (17.1\%), mostly non-white immigrant women and women with disabilities indicated that these needs were not addressed to their satisfaction.

\subsubsection{The attitude of the hospital staff}

Surveyed women were also asked to express how much they agree or disagree with the statement "Hospital staff understands and respect my needs.” Specifically, 33 survey respondents $(47.1 \%)$ indicated that they strongly agree $(n=8)$ or agree $(\mathrm{n}=25)$ with this statement while 21 women $(30 \%)$ neither agreed nor disagreed with the statement. By contrast, 11 respondents $(15.7 \%)$ either disagreed $(n=6)$ or strongly disagreed $(n=5)$ with the statement. The women who disagreed with the statement included non-white Canadian-born and non-white immigrant women, Aboriginal women, bisexual women and women who had disabilities.

\subsubsection{Hospital ambiance and health education materials}

Surveyed women were asked to indicate how much they agree or disagree with the statement "Pictures, posters, and artwork displayed in the hospital reflect my minority status". Only 10 women $(14.3 \%)$ strongly agreed $(\mathrm{n}=2)$ or agreed $(n=8)$ with this statement. Almost three-times more women either strongly disagreed $(n=4)$ or disagreed $(n=24)$ with this statement. This group included immigrant women (both white and non-white), Aboriginal women, women with disabilities and also a lesbian and a bisexual woman. Twenty-nine women (38.6\%) neither agreed nor disagreed with this statement. Furthermore, 30 women $(42.9 \%)$ strongly agreed $(n=7)$ or agreed $(n=23)$ that health education materials used by nurses and doctors reflected their ideas and experiences of health and maternity. By contrast, 18 women (25.7\%) either disagreed $(n=13)$ or strongly disagreed $(n=5)$ with that statement. As in the previous question, this group of women included immigrant women (both white and non-white), Aboriginal women, women with disabilities and also a lesbian and a bisexual woman. Additional 17 women (24.3\%) neither agreed nor disagreed with this statement.

\subsubsection{Patients' consultations}

The final survey question asked participants about the ways by which the hospital staff could consult the users of reproductive health services about their various needs. There were 31 answers recorded in the surveys. Many of these answers suggested that the hospital staff should simply ask about the patients' needs and preferences during the hospital admission or during their first visit to a clinic. The information should be recorded in their file or in the chart. One woman suggested including a section on hospital forms that addresses cultural and religious needs such as, for instance, preferences for male or female practitioners, body parts that should remain covered, birth practices, or food requirements. Other participants suggested that the hospital could collect the information about the needs of their clients by surveys in waiting rooms or email the questionnaires to patients. Several respondents proposed the provision of training in cultural safety for the staff, and recruiting more employees which minority background reflects more closely the background of the patients. An Aboriginal participant suggested that hospital consultants could speak to mothers and families served at various community organizations, such as, for instance, the Odawa Friendship Native Centre or Miinwashin Lodge. Another immigrant woman had a similar approach by proposing the visits to community centres serving immigrant women, such as Catholic Immigration Centre, or Ottawa Community Immigrant Services Organization.

\section{Discussion}

The survey directed at clinical nurse managers indicated that the reproductive healthcare services offered by the Ottawa Hospital are used by a large volume of women of diverse ethnic, cultural, religious, and linguistic backgrounds in addition 
to women with disabilities and women living in non-traditional family arrangements such as single mothers and same-sex couples. However, the review of online hospital sources and the results of managers' survey did not indicate how the women's needs are taken into account in hospital's policies and practices. While the needs of women with disabilities were considered in the Hospital Accessibility Plan, managers had little knowledge of this plan or other existing policies and resources to reduce barriers to inclusion of all minority patients and employees including those with disabilities. It also appears that very little is known about healthcare and information needs of women from various minority groups. Managers were unaware if services offered at the hospital are accessible, appropriate and effective in addressing women's needs. In terms of staff recruitment and retention, there was discrepancy in managers' answers whether the hospital has inclusive hiring policies that eliminate various barriers to employment that some minority groups experience. According to the examined hospital documents, the hospital provides a special training and assessment of employees only in the area of inclusion of persons with disabilities. However, none of the participating managers mentioned this training and assessment in the survey. Similar training and assessment programs in inclusion of other minority groups are apparently unavailable. Diversity-inclusiveness is not an established criterion for appraising staff performance or recognizing volunteers. While, according to the managers, the hospital environment and health education materials generally reflect the needs of minority groups, it appears that there is room for improvement.

The survey with minority women who use reproductive healthcare services in the Ottawa Hospital indicated that the hospital staff had limited knowledge and appreciation of women's cultural health beliefs, values, and practices as well as their linguistic needs. Several women, in particular those with disabilities, indicated that some of their physical and mental needs were also not addressed to their satisfaction. This is of a particular concern since the Ottawa Hospital has in place the above-mentioned Accessibility Plan for reducing the barriers to services experiences by persons who have disabilities. Women from all minority groups expressed similar concerns that the hospital ambiance and health education materials insufficiently reflect their minority status or their ideas about health and maternity.

These findings indicate that there is room for enhancement of diversity-inclusiveness through hospital organizational polices and practices of healthcare professionals. A good point to start would be an organizational self-assessment survey that can look at different aspects of hospital inclusivity. According to a tool kit "Inclusive Community Organization" developed by the Ontario Health Communities Coalition ${ }^{[16]}$ such a survey should include evaluation of several important areas of organizational operations. It is crucial that input to such a survey is sought from both hospital staff and patients. Regarding institutional policy and practice, the survey should examine the effectiveness of existing policies and identify employees' and patients' barriers to inclusion. As for institutional planning of services, the survey needs to include the data about healthcare needs of diverse minority communities within the hospital serviced area and assess whether programs and services for minority communities are accessible, appropriate and effective. The survey should further examine whether the demographic profile of hospital staff, volunteers and hospital partners reflects accurately the profile of clients within the serviced area. Importantly, the survey should assess inclusivity of the hospital physical environment which includes accessibility for patients with disabilities, diversification of displays and health education materials in terms of culture, language, literacy level, or ability, and also the variety of communication styles that the staff members use with patients.

Finally, in the area of professional development, the survey should assess if there are training workshops and programs to increase and measure the knowledge and skills of staff and volunteers in inclusive practice as well as if the indicators of such a practice are included in the performance appraisal. These indicators should encompass assessing five target areas: knowledge of diversity, gender issues, and social determinants of health; knowledge of implications of health beliefs and practices for one's health choices and behaviours; personal self-reflection; social interaction and communication; and also, participation in professional development activities.The findings of hospital self-assessment in these important areas can inform the development of diversity safe, inclusive and universally accessible practices and result in the improvement of the quality of care offered to minority women. However, the continuous evaluation of these practices in terms of their impact on improving patients' health outcomes and satisfaction as well as transforming the hospital environment toward a more inclusive and anti-discriminatory working space will be needed. 


\section{Conclusion}

In this study, we examined the state of diversity-inclusiveness of reproductive health services provided in the Ottawa Hospital because these services are used by a large volume of women from minority communities. This research project supports the findings of other Canadian studies which found that women from minority populations experience reproductive health inequities and have unmet healthcare needs ${ }^{[1-6]}$. The results showed that there is great room for improving hospital inclusivity and equity in all aspects: organization policies, service planning, staff recruitment and training as well as physical environment, and health education materials. Importantly, the improvement of healthcare providers' knowledge in the area of diversity, gender, health equity, various health beliefs and practices as well as their skills in social interaction and communication with minority women would enhance mutual therapeutic relationships. Personal self-reflection and training in anti-discriminatory practice would contribute toward the provision of culturally safe reproductive care for minority women. Our recommendations for a hospital self-assessment of organizational policy and practice can be of particular interest to all hospital decision-makers and service providers interested in increasing inclusivity and accessibility of their institutions. Diversity-inclusive policies and practices can have a positive impact on the health of minority women through the improved quality of service and also contribute toward a healthier and more equitable working environment for hospital employees.

\section{Acknowledgements}

The authors would like to express their gratitude to all research participants and article reviewers for their valuable contributions. In particular, the authors are thankful to Dr. Ivy Bourgeault for her support in securing the ethics approval and a financial contribution to this project. This study was partially funded by the University of Ottawa and the Ontario Ministry of Research and Innovation.

\section{References}

[1] Birch, J., Ruttan, L., Muth, T., Baydala, L. Culturally Competent Care for Aboriginal Women. A Case for Culturally Competent Care for Aboriginal Women: Giving Birth in Hospital Settings. Journal of Aboriginal Health. 2009; 4(2): $24-34$.

[2] Carrasco, C., Gillespie, M., Goodluck, M. Accessing Primary Care in Canada: Giving Voice to the Perceptions and Experiences of Racialized Immigrants. A Systematic Review. Paper presented at the Ethnic and Pluralism Studies Student Conference, University of Toronto, Toronto, ON, Canada. 2009. Available from: http://www.utoronto.ca/ethnicstudies/Carrasco_Gillespie_Goodluck.pdf.

[3] Smith, D. Maternal-child health care in Aboriginal communities. Canadian Journal of Nursing Research. 2003; 35(2): $143-152$.

[4] Spitzer, D.L. They Don't Listen To Your Body: Minority Women, Nurses and Childbirth under Health Reform. In Care and Consequences: The Impact of Healthcare Reform, ed. D.L. Gustafson. 2005; 85-106. Halifax, NS: Fernwood Press.

[5] Kuttai, H. Maternity rolls: Pregnancy, Childbirth and Disability. Black Point, NS: Fernwood Publishing. 2010.

[6] Ross, L., Steele, L, Epstein, R. Service Use and Gaps in Services for Lesbian and Bisexual Women During Donor Insemination, Pregnancy, and the Postpartum Period. Journal of Obstetrics \& Gynaecology Canada. 2006; 28(6): 505-11.

[7] Callister, L. C. What has the literature taught us about culturally competent care of women and children? MCN American Journal of Maternal and Child Nursing. 2005; 30(6): 380-388. http://dx.doi.org/10.1097/00005721-200511000-00006

[8] McManus, A.J., Hunter, L.P., Renn, H.J. Lesbian experiences and needs during childbirth: guidance for health care providers. Obstetric, Gynecologic and Neonatal Nursing. 2006; 35(1): 13-23. PMid: 16466349.

http://dx.doi.org/10.1111/j.1552-6909.2006.00008.x

[9] Lipson, J., Rogers, J. Pregnancy, birth, and disability: Women’s healthcare experience. Healthcare for Women International. 2000; 21: 11-26. PMid: 11022446. http://dx.doi.org/10.1080/073993300245375

[10] Patrick, T.E., Bryan, Y. Research strategies for optimizing pregnancy outcomes in minority populations. American Journal of Obstetrics and Gynecology. 2005; 192(5S): S64-S70. PMid: 15891714. http://dx.doi.org/10.1016/j.ajog.2005.01.075

[11] Van Eijsden, M., Van Der Wal, M.F., Bonsel, G.J. Folic acid knowledge and use in a multi-ethnic pregnancy cohort: The role of language proficiency. British Journal of Obstetrics and Gynecology. 2006; 113: 1446-1451. PMid: 17081188.

http://dx.doi.org/10.1111/j.1471-0528.2006.01096.x 
[12] Wikberg, A., Bondas, T. A patient perspective in research on intercultural caring in maternity care: A meta-ethnography, International Journal of Qualitative Studies on Health and Well-being. 2010; 5(1): 4648.

[13] Carlton, T., Callister, L. C., Stoneman, E. Decision making in laboring women: Ethical issues for perinatal nurses. Journal of Perinatal \& Neonatal Nursing. 2005; 19(2): 145-151. http://dx.doi.org/10.1097/00005237-200504000-00011

[14] Olavarria, M., Beaulac, J., Belanger, A., Young, M., Aubry, T. Cultural Competencies for Health and Social Service Organizations. 2005. Available from: http://www.socialsciences.uottawa.ca/crecs/eng/documents/CulturalCompetenciesforHealthand-05-03.pdf

[15] Nova Scotia Department of Health. A Cultural Competence Guide for Primary Health Care Professionals in Nova Scotia. 2005. Available from: http://www.healthteamnovascotia.ca/cultural_competence/Cultural_Competence_guide_for_Primary_Health_Care_Professionals .pdf

[16] Ontario Healthy Communities Coalition. Inclusive Community Organizations: A Tool Kit. 2004. Available from: http://www.ohcc-ccso.ca/en/inclusive-community-organizations-a-tool-kit

[17] Statistics Canada. Census 2006. Community Profiles. Ottawa (CD). 2006. Available from: http://www12.statcan.ca/censusrecensement/2006/dp-pd/prof/92-591/details/page.cfm?Lang=E\&Geo1=CD\&Code1=3506\&Geo 2=PR\&Code2=35\&Data=Count\&SearchText=Ottawa\&SearchType=Begins\&SearchPR=01\&B1=All\&GeoLevel=PR\&GeoCode $=3506$

[18] Social Planning Council of Ottawa. Living in Ottawa with a Disability. 2006. Available from: http://www.spcottawa.on.ca/sites/spcottawa.on.ca/files/pdf/2006/Publications/Living\%20in\%20Ottawa\%20With\%20A\%20Disa bility\%20English.pdf

[19] The Ottawa Hospital 2011-12 Annual Report. Available from: http://www.worldclasscare.ca/en/at-a-glance/

[20] The Ottawa Hospital. About our hospital. Our promise to you. Available from: http://www.ottawahospital.on.ca/wps/portal/Base/TheHospital/AboutOurHospital/OurPromise

[21] The Ottawa Hospital. Quality and Safety. Planning. Quality Improvement Plan. Available from: http://www.ottawahospital.on.ca/wps/portal/Base/TheHospital/QualityAndSafety/Planning/QualityImprovementPlan

[22] The Ottawa Hospital. Patients \& Visitors. Accessibility. The Ottawa Hospital Accessibility Plan. Available from: http://www.ottawahospital.on.ca/wps/wcm/connect/5961c0804bf3afeb9a67df56b8a72a08/2012+Accessibility+Plan+-+EN.pdf? MOD=AJPERES 